\title{
Amirya, M. dan Atmini, S. 2007. FPENGARUH MOTIVASI KERJA, KONFLIK PERAN, DAN KEPUASAN KERJA TERHADAP KINERJA GURU DI SMP BAHRUL MAGHFIROH MALANG
}

\author{
Oleh: \\ Bambang Septiawan \\ Dosen Fakultas Ekonomi Universitas Islam Balitar
}

\begin{abstract}
Teachers can perform well to accomplish their works influnced by high motivation and work satisfaction as well as minimun task conflict occured. This research is aimed to investigate the influence of work motivation, task conflict, and work satisfaction toward teachers working performance simultaneously as well as partially. This research location is at SMP Bahrul Maghfiroh Malang. Respondents of this research are theachers of the school totally 17 teachers. Data is taken from questionnaire which is separated and filled by the teachers. Then the collected data are analyzed by using SPSS tool(F test and T test) and interpreted by the researcher. The result of this research proves that first, work motivation, task conflict, and work satisfaction influence simultaneously teachers working performance significantly. Second, work motivation influences partially working performance significantly. Third, task conflict influences partially working performance significantly. Fourth, work satisfaction influences partially working performance significantly.
\end{abstract}

Key words : work motivation, task conflict, work satisfaction, and teachers working performance.

\section{PENDAHULUAN}

Tugas utama seorang guru adalah mendidik para peserta didiknya. Menurut undang undang no 14 tahun 2005 tentang guru dan dosen pasal 6 mengatakan bahwa kedudukan guru dan dosen sebagai tenaga profesional bertujuan untuk melaksanakan sistem pendidikan nasional dan mewujudkan tujuan pendidikan nasional yaitu berkembangnya potensi peserta didik agar menjadi manusia yang beriman dan bertaqwa pada Tuhan Yang Maha Esa, berakhlak mulia, sehat, berilmu, caka, kreatif, mandiri, serta menjadi warga negara yang demokratis dan bertanggung jawab.

Selanjutnya guru juga harus menjalankan fungsi organisasi sekolah. Peraturan Menteri Pendidikan Nasional no 19 Tahun 2007 Pasal 1 bahwa satuan pendidikan wajib memenuhi standard pengelolaan pendidikan yang berlaku secara nasional. Peraturan tersebut selanjutnya di jabarkan jika 
struktur organisasi sekolah/madrasah berisi tentang sistem 1 penyelenggaraan dan administrasi yang diuraikan secara jelas dan transparan.

Setiap tindakan guru dalam organisasi pendidikan tentunya memiliki motivasi tertentu. Menurut Gultekin (2014) menyebutkan jika motivasi terkait dengan bagian komplek dari perilaku fisik dan mental. Motivasi guru membuat guru melakukan sesuatu (mungkin bernilai atau tidak bernilai) untuk mencapai tujuan mereka. Kemudian Sunyoto (2013) mengatakan motivasi kerja adalah sebagai keadaan yang mendorong individu untuk melakukan kegiatan-kegiatan tertentu untuk mencapai keinginannya.

Lebih dari itu, dalam sebuah organisasi yang sering terjadi antar guru adalah konflik peran, dimana mengharuskan setiap orang sering kali ditugaskan untuk melakukan hal diluar tugas pokok dan kemampuannya. Sunyoto (2013) mendefinisikan konflik sebagai ketidak setujuan antara dua atau lebih anggota organisasi yang timbul karena harus menggunakan sumber daya yang langka secara bersamaan. Dibalik itu mereka mempunyai status, tujuan, dan persepsi yang berbeda. Kemudian Mc Shane (2005) menjelaskan konflik adalah sebuah proses dimana satu kelompok merasa bertentangan dengan kelompok lain.

Oleh karena itu muncul perselisihan antara harapan yang berkaitan dengan suatu peran. Sebagai contoh seorang guru bahasa inggris yang diberi tugas tambahan mengajar olahraga dan tugas fungsional sebagai bendahara. Lazimnya orang tersebut mendapat jam mengajar bahasa inggris dan tugas sebagai waka humas yang lebih cocok dengan kompetensinya. Hal ini nantinya akan berkaitan juga dengan kepuasan para guru dalam bekerja serta kinerjanya.

Kepuasan kerja merupakan sebuah bentuk sikap guru terhadap apa yang mereka peroleh dan lakukan dalam sebuah organisasi sekolah. Amstrong (2009) mengungkapkan bahwa kepuasan kerja adalah sikap atau perasaan manusia tentang apa yang mereka kerjakan. Sikap positif mengarah pada tindakan untuk melaksanakan tindakan kerja dengan tepat, dan itu disebut kepuasan kerja. Sikap negatif mengacu pada ketidakpuasan dalam pekerjaan.

Pekerjaan ganda atau tugas yang tak sesuai dengan kompetensi guru, lazimnya akan membuat kepuasan kerja mereka akan menurun. Walaupun demikian, tidak selamanya hal tersebut terjadi. Penelitian yang dilakukan Merz dalam Peters (2013) menemukan hasil yang mengejutkan jika beban kerja berlebihan seorang guru bukanlah indikator utama dalam hal kepuasan dalam bekerja. Oleh karena itu, pekerjaan ganda belum tentu menurunkan tingkat kepuasan kinerja guru yang nantinya akan berdampak juga terhadap kinerja mereka.

Kinerja merupakan output dari rencana dan hal-hal yang tercapai menurut standart tugas yang telah ditentukan. Menurut Amstrong (2009) kinerja adalah apa yang telah diraih dan bagaimana cara meraihnya. Kinerja guru merupakan perwujudan nyata dari aspek-aspek yang 
mempengaruhinya. Kinerja guru akan sangat berperan besar pada kemajuan anak didik dan organisasi sekolah.

Peneliti melakukan riset di lembaga pendidikan yakni SMP Bahrul Maghfiroh Malang yang merupakan sekolah dan mengalami proses berkembang untuk menjadi organisasi mampu mencapai top level.

SMP Bahrul Maghfiroh merupakan pendatang baru di dunia pendidikan Kota Malang. Sekolah yang telah berdiri sejak tahun 2011 ini terus melakukan perubahan dan inovasi untuk menjadi lembaga pendidikan yang unggul. Salah satunya meningkatkan kemampuan guru dengan memberikan pelatian-pelatian, melengkapi fasilitas, peningkatan kesejahteraan guru, dan lain sebagainya. Hal itu ditunjukan agar para guru mempunyai motivasi yang tinggi dalam bekerja. Hal tersebut nampaknya berhasil dengan diraihnya prestasi masuk 3 besar juara Lomba Penelitian Ilmiah Remaja selama 2 tahun berturut-turut, kelulusan selalu 100\%, juara lomba banjari, dan lainya. Tetapi, semua itu belum terlengkapi semuanya sesuai goal setting organisasi dan hal ini pastinya berpengaruh pada motivasi guru, sehingga peningkatan pemberian motivasi harus terus diupayakan.

Selain itu, guru yang ada di SMP Bahrul Maghfiroh memiliki beban tugas ganda, yaitu mengajar (memberikan materi pelajaran), mendidik (membentuk karakter dan akhlak anak didik menjadi mulia), dan menjalankan peran organisasi. Bahkan ada beberapa guru yang harus mengajar dua mata pelajaran yang berbeda, salah satu alasan utamanya adalah efisiensi pengeluaran biaya operasional dan perencanaan program sekolah yang masih belum maksimal. Dampaknya, ditengah masa proses pembelajaran dan keorganisasian banyak hal yang tak terduga terjadi tanpa antisipasi sebelumnya. Tentunya hal ini akan memicu konflik peran di samping mereka juga harus menjabat sebagai kepsek, wakasek, bendahara, dan sebagainya. Konflik yang muncul menyebabkan adanya dua kemungkinan, yaitu meningkatkan kinerja mereka atau malah melemahkannya.

Konflik yang muncul baik positif maupun negatif, pasti memunculkan sikap kepuasan kerja bagi para guru. Kepuasan itu mengantarkan pada kinerja meraka yang mungkin baik tapi juga bisa buruk. Sehingga sekolah ini nantinya semakin bertambah maju atau sebaliknya. Oleh sebab itu, penulis ingin meneliti keterkaitan ketiga faktor tersebut dengan kinerja guru di SMP Bahrul Maghfiroh berdasarkan realita dan kondisi lapangan yang telah dijelaskan.

Tujuan penelitian yang hendak dicapai adalah :

1. Untuk menganalisis ada tidaknya pengaruh motivasi kerja terhadap kinerja guru di SMP Bahrul Maghfiroh Malang.

2. Untuk menganalisis ada tidaknya pengaruh kepuasan kerja terhadap kinerja guru di SMP Bahrul Maghfiroh Malang.

3. Untuk menganalisis ada tidaknya pengaruh konflik peran terhadap kinerja guru di SMP Bahrul Maghfiroh Malang.

4. Untuk menganalisis ada tidaknya pengaruh motivasi kerja, konflik 
peran, dan kepuasan kerja terhadap kinerja guru di SMP Bahrul Maghfiroh Malang.

Manfaat dari penelitian ini yang pertama, Dapat digunakan sebagai literature atau referensi baru bagi mahasiswa sekaligus informasi yang bermanfaat khususnya mengenai motivasi kerja, konflik peran, dan kepuasan kerja terhadap kinerja guru. Kedua, Bagi sekolah, dari hasil penelitian ini, diharapkan dapat digunakan sebagai masukan dalam upaya pembinaan dan pengembangan guru secara efektif, sehingga mendukung pencapaian tujuan program pendidikan dan organisasi. Ketiga, Bagi guru atau pendidik, dari hasil penelitian ini, diharapkan dapat digunakan sebagai bahan acuan dalam rangka peningkatan kinerjanya. Terakhir, Dapat digunakan sebagai sumber informasi dalam memahami tentang motivasi kerja, konflik peran, dan kepuasan kerja terhadap kinerja guru.

\section{METODOLOGI PENELTIAN}

Waktu pelaksanaan penelitian akan dilakukan pada bulan 1 Mei 2015 sampai dengan 17 Mei 2015. Sedangkan lokasi penelitian berada di SMP Bahrul Maghfiroh Jalan Joyo Agung Atas Nomor 02 Tlogomas Lowokwaru Kota Malang.

Untuk mendapatkan hasil penelitian yang maksimal dan komprehensif, peneliti menggunakan pendekatan kualitatif dan kuantitatif dengan menitik beratkan pada kuantitatif. Selanjutnya, peneliti akan menggunakan metode kausal. Metode ini merupakan riset yang bertujuan untuk membuktikan hubungan sebab akibat dari variabel-variable yang diteliti (Istijanto, 2006). Dalam penelitian ini di gunakan untuk melihat pengaruh motivasi, konflik peran, dan kepuasan kerja terhadap kinerja guru.

Populasi dalam penelitian ini sekaligus sampel yang digunakan untuk penelitian yakni 17 guru SMP Bahrul Maghfiroh. Hal ini dilakukan karena jumlah populasi yang tidak terlampu besar dan mudah untuk diteliti. Untuk mendapatkan data dan informasi, peneliti menggunakan data primer yang berupa survei (angket atau kusioner) dan wawancara serta data sekunder internal (data perangkat pembelajaran, absen dan prestasi guru).

Langakah-langkah dalam teknik analisis data adalah pertama Kuesioner yang akan digunakan sebagai alat pengumpul data terlebih dahulu diuji validitas dan reliabilitasnya. Pengujian ini dimaksudkan untuk mengukur tingkat kelayakan kuesioner sebagai alat pengumpul data. Kedua, analisa deskriptif bertujuan untuk memberikan gambaran mengenai suatu data agar data yang tersaji menjadi mudah dipahami dan informatif bagi orang yang membacanya. Ketiga, uji asumsi klasik dan regresi linier berganda bertujuan untuk memberikan gambaran mengenai suatu data agar data yang tersaji menjadi mudah dipahami dan informatif bagi orang yang membacanya.

Dalam penelitian ini variable (X1) adalah motivasi kerja, (X2) konflik peran, $(\mathrm{X} 3)$ kepuasan kerja, kemudian $(\mathrm{Y})$ adalah kinerja guru. 
HASIL DAN PEMBAHASAN

Tabel 1

Hasil Estimasi Pengaruh Motivasi Kerja, Konflik Peran, dan Kepuasan Kerja Terhadap Kinerja Guru

\begin{tabular}{|c|c|c|c|c|}
\hline \multicolumn{2}{|c|}{ Variabel Jefisien } & \multirow[t]{2}{*}{ StandardizedCoeffisient } & $\begin{array}{c}\text { Tstatisti } \\
c\end{array}$ & Prob \\
\hline Konstanta & 1.374 & & 2.347 & 0.035 \\
\hline 1otivasi Kerja & 0.404 & 0.384 & 2.817 & 0.015 \\
\hline 〈onflik Peran & -0.287 & -0.394 & -3.454 & 0.004 \\
\hline $\begin{array}{c}\text { Kepuasan } \\
\text { Kerja }\end{array}$ & 0.558 & 0.540 & 3.960 & 0.002 \\
\hline $\begin{array}{l}\text { Fstatistic } \\
\text { R-squared }\end{array}$ & $\begin{array}{l}=24.485 \\
=0.850\end{array}$ & $\begin{array}{c}\text { Prob } \\
\text { Adj. R-squared }\end{array}$ & $\begin{array}{l}=0.000 \\
\quad=0.815\end{array}$ & \\
\hline
\end{tabular}


Berdasarkan analisis penelitian dapat dibuktikan jika motivasi kerja (X1), konflik peran (X2), dan kepuasan kerja (X3) secara simultan maupun parsial. berpengaruh signifikan terhadap kinerja guru $(\mathrm{Y})$.

Tidak bisa dipungkiri jika motivasi akan memberikan dampak besar kepada kinerja guru. Gaji yang besar bukan faktor tunggal yang mampu mendongkrak kinerja. Berdasarkan penelitian ini guru di SMP Bahrul Maghfiroh akan lebih termotivasi jika faktor instrinsik mereka lebih terpenuhi seperti yang di ungkapkan Herzberg dalam teorinya.

Guru akan bekerja maksimal dan merasa puas jika mereka mendapatkan penghargaan jika berprestasi, mendapat supervisi dari kepala sekolah, dan mendapatkan pelatihan untuk meningkatkan prestasi mereka sehingga mereka memiliki karir yang terus meningkat. Mc Clelland mengungkapkan bahwa kebutuhan akan prestasi dan kekuasaan akan mampu mendorong guru untuk lebih meningkatkan kinerjanya.

Oleh sebab itu gaji yang cukup, lingkungan kerja yang baik, hubungan kepala sekolah dan guru yang hangat serta saling support merupakan hal dasar yang memang harus dipenuhi. Jika tidak mereka akan merasa tidak puas dan menurunkan kinerjanya. Namun, jika hal tersebut telah dilakukan, kemudian kepala sekolah mampu memberikan penghargaan atas prestasi guru, melakukan bimbingan atau supervisi guru untuk meningkatkan kinerjanya, dan pemberian tugas yang sesuai dengan kapasitas guru maka faktor-faktor itu mampu memberikan motivasi yang kuat untuk memberikan dorongan pada guru agar kinerjanya lebih maksimal.

Konflik peran atau konflik tugas guru pastinya akan berdampak pada kinerja mereka. Guru di SMP Bahrul Maghfiroh mayoritas harus melakukan tugas ganda. Contohnya kepala sekolah juga diwajibkan mengajar meski jam tidak sebanyak guru biasa dan guru PAl yang merangkap mata pelajaran Pkn. Tentunya berdasarkan hasil analisa terbukti bahwa tugas ganda yang di alami guru akan berdampak pada kinerja mereka meskipun hal itu pengaruhnya tidak sebesar variabel lain dalam penelitian ini.

Guru di SMP Bahrul Maghfiroh menjadikan konflik sebagai sebuah tantangan untuk bekerja lebih baik walaupun demikian fakta ini akan tetap mempengaruhi kinerja mereka untuk mencapai tujuan dan hasil yang telah ditargetkan. Menurut Robbins (2013) mengemukakan salah satu penyelesaian konflik yakni dengan cara kolaborasi. Guru di SMP ini saling nertukar pikiran dan membentu satu sama lain untuk menyelesaikan konflik yang mereka hadapai.

Jadi dari konflik yang di hadapi Guru SMP Bahrul Maghfiroh mampu memberikan hasil yang positif untuk semua pihak, karena mereka semua bertekad untuk memajukan organisasi bersama. Hal itu sama seperti yang di ungkapkan Sunyoto (2013) semua pihak guru yang mempunya tugas ganda sama-sama diuntungkan. Namun tetap harus di cemati jika konflik peran yang mereka hadapi semankin besar tentu saja pengaruhnya terhadap kinerja mereka juga akan tinggi.

Kepuasan kerja merupakan elemen penting yang mempengaruhi 
kinerja guru. Dari analisa dapat di kemukakan bahwa tingakat kepuasan guru sudah bisa dikatakan tinggi. Oleh karena itu mereka mampu menghasilkan kinerja yang baik. Menurut Robbins (2013) Kepuasan kerja guru merupakan kunci pendorong moral kerja, kedisiplinan dan prestasi kerja guru dalam mendukung terwujudnya tujuan sekolah. Sehingga, faktor -faktor pendorong kepuasan kerja memang harus ditingkatkan.

Mayoritas guru di SMP Bahrul Maghfiroh tergolong usia muda dan produktif. Di usia mereka yang masih muda mereka mendapat banyak kesempatan untuk berkarya yang jarang dimiliki oleh orang-orang seusia mereka. Menurut hasil penelitian ini mereka merasa cukup puas dengan apa yang di berikan lembaga. Mereka merasa sudah sesuai antara tugas yang diberikan dengan kompensasi yang mereka peroleh. Oleh karena itu, kepuasan kerja yang sudah baik semestinya harus di tingkatkan untuk memacu kinerja mereka berjalan lebih maksimal lagi.

Dari hasil pengujian koefisiensi determinasi diketahui jika motoasi kerja, konflik peran dan kepuasan kerja berpengaruh $81.5 \%$ terhadap kinerja guru dan sisanya $18.5 \%$ variabel lain yang tidak dibahas dalam penelitian ini. Data ini menunjukkan jika ketiga varibel tersebut berpengaruh besar terhadap kinerja guru. Dengan demikian variabel motivasi dan kepuasan harus di tingkatkan agar dan konflik peran atau tugas harus di minimalisir agar kinerja guru bisa maksimal.

\section{KESIMPULAN}

Berdasarkan pembahasan pada bab yang telah diuraikan sebelumya, maka dapat ditarik kesimpulan sebagai berikut:

1. terdapat pengaruh signifikan motivasi kerja terhadap kinerja guru.

2. berarti terdapat pengaruh signifikan konflik peran terhadap kinerja guru.

3. terdapat pengaruh signifikan kepuasan kerja terhadap kinerja guru.

4. terdapat pengaruh signifikan secara simultan (bersama-sama) motivasi kerja, konflik peran, dan kepuasan kerja terhadap kinerja guru.

\section{DAFTAR PUSTAKA}

Undang-Undang Nomor 14 Tahun 2005 dan Peraturan Menteri Pendidikan Nomor 19 Tahun 2007. Melalui www.kemenag.go.id

UU 19 Tahun 2005. Melalui www.sipma.ui.ac.id/files/dokumen/

Gultekin, H. \& Acar, E. 2014. The Intrinsic and Extrinsic Factors for Teacher Motivation. vol. 48 291-306. Rumania: Expert Projecs Publishinh House. www.doaj.org

Sunyoto, D. 2013. Teori,Kusioner, dan Proses Analisis Data Perilaku Organisasional. Yogyakarta: CAPS.

Mc Shane, S.L. \& Von Glinow M.A. 2005. Organizationa Behaviour: Emerging Realities for The Workplace Revolution. New York: Mc Graw Hill.

Amstrong, M. 2009. Amstrong's Handbook of Human Resource Management Practice $17^{\text {th }}$. London: Kogan Page. 
Istijanto. 2006. Riset Praktis Sumber Daya Manusia. Jakarta: PT S

Peters, J. 2013. Workload, Stress and Job Satisfaction Among Waldorlf

Teacher. vol.3 no.2 111-117. www.rosejourn.com

Robbins, S. P. \& Judge, T. A. 2013. Organizational Behaviour. New Jersey: Pearson Education 